\title{
A GENERAL INTRODUCTION TO THE SEISMIC DESIGN PROBLEM
}

R. J. P. Garden*

\section{Editorial Foreword}

This paper is reproduced from the proceedings of a seminar on "Seismic Problems in Structural Engineering" arranged by the Departments of Civil Engineering and Extension studies of the University of Canterbury, and held in Christchurch from May 13 to 16. 1968. The paper was presented in the opening session of that seminar, and because of its wide and interesting range is now published in the Society's Bulletin.

\section{Introduction}

The most notable feature of the General Problem is that so much remains to be done. The great advances that have been made in the last 15 years have emphasised the inadequacy of our knowledge of aspects still to be solved.

The path to be followed by the Designer was, a short time ago, a route for a rugged tramper who had to reach his destination by primitive means of travel. Today, parts of that route have been built up to modern highway standards suitable for sophisticated vehicles. Some deep waterways have been bridged. Between these established reaches of firm going, there remain lengths of jungle path and unstabilised swamp which have yet to be tamed by scientific attack.

However, the progress has been real and the rate is increasing, and it is likely that regularised procedures will be established for dealing with all aspects of the problem in the next twenty years.

When that day comes, this field of study will have lost much of its fascination for men of the type of the lecturers in this seminar. It is these present years that are rich in the thrills of discovery and creation for those who dedicate time to the seismic design problem. The history of technical and scientific development shows that surges of special progress have occurred intermittently throughout the centuries. Referring for the moment only to structural design there has been a spurt of progress in our time initiated 40 years ago when Hardy Cross presented designers with a new and vital aesthetic conception of structural analysis.

* Partner in E.R. Garden \& Partners, Consulting Engineers, Dunedin. 
It is not too much to say that the recent activity in New Zealand constitutes an output which is quite impressive in relation to the size of our country. The importance of this lies not so much in what these efforts will contribute to the world's knowledge of seismic design, as in the stimulation it must give to our technical culture. Enthusiastic dedication of this kind is of incalculable value to our community.

\section{Sections of the Problem}

In meeting my assignment to review the general problem, some aspects are first enumerated in which the lack of sufficient knowledge is most obvious.

\section{Origin of Earthquakes}

It may not be possible to state our problem properly until the origin of earthquakes is understood in embryo but this aspect cannot be dealt with in this context.

\section{Surface Motions}

Next in order, up towards the grass roots, we have great inadequacy in understanding the nature of seismic ground motions. Dr F.F. Evison said at III W.C.E.E. (1) "amassing data directly relevant to building design has scarcely begun".

Unfortunately, the seismologists have been able to make the same kind of statement for many years past. It is understandable that geophysicists have not interested themselves particularly in the mechanics of disturbances in the surface layers of the earth and there are indications that we are more likely to get progress in this from studies carried out by engineers. It has been difficult to understand what reason anyone could have for expecting to find any useful relation between the instrumentally assessed total energy of an earthquake and the intensity of felt effects. At first, the relations that were proposed were relevant to a restricted set of conditions. More recently progress has been made in extending the relation to take into account the particular conditions of local regions.

\section{Microzoning}

The relation between Intensity and Magnitude (at least for Intensities at some distance from the epicentre) can be more reasonably explained when the effect of layers above bedrock are taken into account. An address 
Conference in Christchurch by Shepherd and Travers would arouse the interest of any reader in this line of investigation, and I hope this address will appear in print. There has been a great deal of significant work published both overseas and in New Zealand on this subject of microzoning. Microzoning includes a study of each local region to determine the effects of superficial layers upon the Intensities of motion which would occur at the surface as a result of seismic waves transmitted from the crust. It is well known that the presence of layers of soft or loose material can magnify the surface Intensities considerably. Investigations in Russia revealed a magnification of amplitude of 4 to 6 times. The Caracas earthquake of July, 1967 caused severe damage in localised areas.

It seems doubtful if money can be wisely spent upon a network of strong motion recorders unless this is accompanies by a vigorous programme of microzoning to cover at least the more important localities of our country.

\section{Interaction of Structure and Soil}

Useful reviews of work done on this problem have been produced in this University. (Shepherd and Walpole, (3) Shepherd and Donald (4)). Accounts of more intensive studies of particular soils have been issued from Auckland (Taylor et al and Taylor (6)).

On this subject we have no guidance or instructions in our codes or textbooks, and yet it is as important for determining the forces on our buildings, as the whole of our present codified procedure for assessing structural forces.

Without reaching the level of the structure two out of three aspects of the Design Problem in which we are most in need of enlightenment, come to our attention.

\section{Forces Stipulated in our Codes}

When our present Loadings code(7) was drafted the foreword stated that a modified El Centro spectrum (damping 10\% and a ductility factor of 4 ) defines the co-efficient considered appropriate to public buildings in Zone A. How good is this El Centro spectrum as a basis for New Zealand design rules? It was the only good record of a strong "quake available, it has therefore a great importance, but its significance will not be known until strong motion records of different types of severe earthquakes are available. 
What expectation is there that further records will differ significantly? It is quite clear from past history that the destructive action of earthquakes can vary greatly in nature and distribution from that displayed at El centro. Some ratings of the El Centro 'quake are - intensity MM IX and maximum ground acceleration $0.33 \mathrm{~g}$. In Assam complete devastation has been caused over areas up to 9,000 square miles, which indicates intensities much greater than the MM IX of El centro. There are no good reasons to believe that the shapes of response spectra in such conditions would closely resemble that of $\mathrm{EI}$ Centro. In Assam, also, boulders have been projected up out of their sockets in the soil and vertical accelerations of $1.2 \mathrm{~g}$. have been assigned. To the Kwanto Earthquake is ascribed horizontal acceleration of $0.5 \mathrm{~g}$. for waves or periods of order 1 second or greater.

If strong motion records had been obtained of these earthquakes, instead of El Centro, one wonders how our code writers would have squared the evidence with their ideas of design co-efficients appropriate to New Zealand. No doubt a modified design curve of agreeable shape could be produced, given sufficient goodwill.

There is also the apparent fact that earthquake destruction is not infrequently caused by a sudden unrecovered displacement of part of the crust. It is fashionable to attend to the calculated effects of elastic ground motions in disregard of the effects of possible sudden ground displacements of considerable magnitude. The code makes a good deal of the question of limitations on drift of structures. It could be harmful to divert the designer's attention from the importance of considering how his structure will accept large strains. It would be helpful to know the duration of and magnitude of the single large impulses which observers have reported at Agadir, Skopje, Fukui, etc.

When a start was being made to review our previous Loadings code, it was suggested that it would be desirable to eliminate the use of the Base shear co-efficient as a fundamental parameter. It was perhaps too early, at that time, to make this change. Do you think the time has yet arrived to make this change appropriate? If the use of base shear parameters were dispensed with, we would have to start below the grass roots in establishing the horizontal forces appropriate to any structure. This could be done by steps somewhat as follows :- 
First establish expectable seismic motions in the local basement rock;

Second evaluate the effects of local layers overlying the basement to obtain the nature of seismic motion at the surface:

Third include the quasi elastic mass of the supporting soils in with the mass of the structure, in determining the response of the building.

The first two steps are involved in the matters of zoning, micro-zoning and other aspects. When we were promoting the practice of establishing zones of seismicity we had difficulty in persuading our opponents to give the question the detached scientific consideration it should receive. The arguments were often coloured by the fear that engineers would misuse the results; by the fear that some event would seem to prove that there was some neglect of every precaution to save life; by confusion over local soils, which should be left to the field of micro-zoning. There was wide approval of the idea that micro-zoning should be carried out.

You may well object that the data are not available for a proper evaluation of response by these steps. However, you could scarcely maintain that a rough assessment of the effects of these matters would give a worse answer than obtained by ignoring them completely. Our present co-efficients give average figures unadjusted by any consideration of local soil conditions or of interaction between soil and structure.

To be honest it must be admitted that the magnitude of the horizontal forces required by our present code were based upon world experience of building performance and not upon instrumental records of ground motion, though the degree of variation of force with natural period was derived from instrumental records. It is not suggested that we are in a position yet to dispense with data yielded by past average performance of buildings for determination of the average degree of earthquake resistance to be required in our code. Therefore the calculated responses to be obtained from the new procedure would still be factored by a quantity of value such that the median or average would accord with the present requirements.

It may have been thought that zoning proposals advocated in the past, by engineers in my home area were motivated by an unjustifiable if not criminal desire to reduce the safety of their local designs. However, proposals for zoning were accompanied by the suggestion that the curves to relate seizmic coefficient with period should have a different shape for 
different zones. It was suggested that proportionately less reduction for long period motions would be appropriate for zone ' $C$ ' because information available at that time indicated that long period buildings on soft ground did not obtain the relief due to distance from areas of seismic activity to the same extent as did buildings and soils of stiffer types. Pending the implementation of microzoning it would be wise to take a conservative view of code requirements for long period buildings in Zone $\mathrm{C}$.

One result from this change which would be of ultimate benefit is that we practical designers would be forced to think logically about matters we often ignore. Another benefit is that the need for microzoning would be constantly brought before us. A separate reason supporting the proposal is that responses at various levels in a building do not vary linearly with the value of base shear.

If is difficult to be impressed by the claim that imprecision would be introduced by incorporating these parameters concerning soils. Studies in structural dynamics have given an appearance of precision to our design, but this is lost in many other features tributary to the problem.

\section{Analysis and Design of Structures}

A detailed account of local achievements in this field follows and at this stage only a few specific points are mentioned.

\section{Torsion}

Dynamic analysis of elastic models surely shows that when torsional effects of eccentricity are coupled with horizontal oscillations the calculated forces to be borne may be greatly increased. It appears also that the characteristics of the elastic resonator are sensitive to small variations of damping and distribution of live loading. Another doubtful quantity is the amount of torsional movement in the incident ground motions. The threat from inadequate determination of torsion effects may have appeared so great that this alone justified a very conservative attitude. True enough, structural damage is often ascribed to torsion, and this may truly be of high importance. However, practical evidence on this point could not be accepted unless the case histories were properly examined to eliminate other reasonable explanations for the damage and to pursue the point we would need to consider buildings which are nominally concentric. 
To look at the problem in another way, the degree of strength which we have learnt by experience to be sufficient for reasonable resistance to earthquake has been arrived at from the behaviour of buildings in which inherent or accidental eccentricity has without doubt often been present. If we now take advantage of means newly available for dynamic torsional analysis and provide extra strength in proportion to the newly calculated threat, would we not be adding over again for a circumstance which is already allowed for in our basic coefficients? The rule-of-thumb man would find in this, further justification for his belief that detailed calculations serve only to increase ones headaches. Meantime, he may be right, but this is only because some aspects of analysis have developed further than other branches of the problem and when the other studies catch up, science will replace art.

Whether we design by rule of thumb or by using all the digits, the shape and style of structure have a big influence on safety against trouble from torsion.

\section{Secondary Damage}

While flexibility in a building serves to protect it from destruction, this same attribute can cause expensive damage to elements other than the main structure. In order to reduce such damage our code(7) limits inter-storey deflection to $0.0025 \mathrm{x}$ storey height for wind and earthquake, which may be doubled where adequate clearances are provided for all non-structural elements. For a $12^{\circ}$ storey height this means $3 / 8^{\prime \prime}$ or when doubled $3 / 4^{\prime \prime}$. It is questionable that there is evidence that secondary damage from seismicity in New Zealand, in buildings designed to any reasonable code, will be such an expensive matter as to merit any great expenditure in attempts to prevent it. In the past 100 years, with most buildings not designed in any way to resist shocks, the damage has not been high. Had all our buildings been designed with some reasonable earthquake resistance, the damage toll would have been rather slight. There can be little objection to providing some further protection against secondary damage provided the cost of such protection is reasonable. But it is recognised that increased rigidity invites greater seismic forces, and to limit deflections and at the same time specify rather high seismic co-efficients can be rather costly. It is doubtful if the combination of elastic strength and rigidity required by the code is justified.

The code requires rather severe co-efficients, for seismic loading; it requires the designer to provide a building which will not deflect much under these severe loads; it stipulates design stresses for these loads such that the building will 
behave in a substantially elastic manner under much higher lateral loading. It is claimed in the Draft the co-efficients have been derived using a ductility factor of 4 . This is as good as saying that, unless considerable post-elastic yield takes place the lateral forces will be much greater than represented by the design co-efficients given in the Draft. But, to develop a ductility factor of 4 , the deflections of the building would have to be at least 8 times and, depending on non-codified features of the design, would sometimes have to be considerably greater than 8 times those allowed in the Draft.

Does this then mean the code requirements will provide buildings which are stiff elastic resonators which will respond violently to ground motions? If this is the case then the principal effect will be that the requirements that have been included for the purpose of preventing damage will fail to achieve that end.

It is possible that Secondary Damage in the future will in fact be a big item. Is there an assurance that we will not suffer from Tsunami damage? It is possible that the cost of Tsunami damage and also fire damage deserve more of our attention than damage caused by motions of our buildings.

Despite improvements already achieved, unsuitable details still abound in our structures. Evidence of this is reported from every damaged town, but past experience cannot provide all the answers. In a given building, if one weakness is strengthened, forces are likely to be accentuated at some other place. If a building of proven worth is duplicated, some change in detail could change the pattern of damage. The adoption of new materials, new styles of construction and new methods of making joints can bring new problems for which past experience is not directly applicable. We can, of course go some way towards the correct treatment of details by using mathematics and intuition, both used to build upon the knowledge gained from past experience. Pursuit of the best solution can bring problems. The engineer may have to decide if he should advise the architect that some feature such as a strong room should be changed to a less convenient location in order to reduce the risk of minor structural damage. One likes to have a firm conviction of the truth of one's prognosis before imposing onerous requirements on the planning.

To those who insist that protection against secondary damage should be stipulated in our codes, the never ending complexity of the problem should be emphasised. The best 
solution, even the ideal solution, which we should aim to approach, certainly does not consist of having all secondary features of a building designed so that the limit of their undamaged resistance is reached under motions of a designated severity. Some features may be protected by inexpensive provisions while some would require expense out of proportion to their worth. The cost of extra design fees needed for really thorough consideration of minor and secondary damage might well be great enough to finance complete insurance cover for the amount of secondary damage to be reasonably expected in New Zealand.

\section{Faulty Workmanship}

Reports of earthquake damage, and of other failures, coming from other countries describe a surprising number of cases of faulty materials, wrong practices, omitted reinforcement etc. Standards of construction in this country are relatively high.

\section{Responsible Design}

Many earthquake disasters have brought to light that designers have failed to comply with current codes. An eminent overseas engineer told me he had been engaged by a prospective purchaser to report on a large building and his report was unfavourable because he found the structural design inadequate. It is doubtful if a similar case could be found in New zealand. From one who has studied damaged buildings in Alaska and had studied the structural drawings came the comment that, if he got his pencil real sharp, he could show that the designs complied with the letter of the code, even when he considered them substandard designs. How do our standards of design compare with these? Our earthquake resistant designs have not yet been put to the test. While it is certain that a severe test would reveal weaknesses, it could be expected that most of our local work would behave quite creditably.

\section{Materials of Construction}

\section{Concrete Pros and Cons}

The most common material in our structures is concrete. This material is cheap: it may conveniently be shaped as desired; it is fire resistant; it is sound resistant; it has useful thermal storage, fair compressive strength and contributes usefully towards the damping of oscillations; structural continuity is easily obtained. Against all these advantages, we have the disadvantage of very poor tensile properties. Concrete has low tensile strength but worse still, because it does not exhibit 
strain hardening, it lacks ductility. A fortune awaits the man who can produce a ductile concrete at reasonable cost, even if it has no greater tensile strength than at present.

Meeting the Deficiencies

In the design of concrete work we have developed a great many procedures, forced upon us one after another by deficiencies in tension. We have to control shrinkage and temperature shortening effects, we have to use steel reinforcement for direct tension and for secondary tension forces: tension stresses in steel have had to be limited to avoid too severe cracking of concrete; our main reason for using prestressing procedures is to counter the weakness of concrete in tension.

\section{Deficiency Remains}

But all these precautions do not eliminate the fact that we have still to rely upon such tensile strength as our concrete can provide. Without it each structure would immediately crumble to a mass of rubble. Under the dynamic response from earthquakes the lack of ductility is a pronounced drawback, and has to be taken into account in prestressed concrete, normal reinforced concrete and in reinforced blockwork.

\section{Steel and Concrete - Combined and composite}

Most commonly, the steel is combined as reinforcing or prestressing. We also have composite members where the materials have a less intimate association in sharing the forces. The Japanese have employed latticed steelwork encased in reinforced concrete but it is doubtful if this system merits general adoption. It has been found useful for erection purposes and has been used also in slender ribs forming architectural features on columns with the object of conferring ability to survive on these features which would otherwise be expected to behave badly once the concrete cracked. We have also been interested locally in composite or combined action of steel tube columns filled with concrete. $(8,9)$ It has been shown that combined action is lost because the increase in steel diameter exceeds increase in diameter of the concrete core. If some kind of auto-frettage could be applied the composite member would become a combined unit with improved performance.

\section{Steel and Concrete - Mixed Construction}

Many examples exist such as steel frame - plus shear wall structures, and no doubt there is scope for inventiveness in this field. There is an obvious case for frames made mainly of concrete, but changing to steel near each joint, 
provided the joint sections do not cost too much. The subject of mixed construction involves matters to be discussed under styles of structure.

\section{Styles of Structure}

Space will be taken to discuss a few points of interest.

\section{Prestressed Floor Units}

We all know of the deficient inter-connections revealed by damaging earthquakes. The cost of transverse stressing is justified in many cases. If there is to be any cast-in-place topping, one should give thought to making this as effective as possible in connecting the units and in arriving at a good disphragm. Systems which have no precast top flange and have the whole slab section cast in place can provide a good diaphragm. The flanges of precast Tees should not be unnecessarily thick, so that as great a proportion of total thickness as practicable is cast in place. There are several criticisms of the use of prestressed double Tees placed close against each other, and use has been made of units with heavier ribs and spacing the units apart. In the precast unit this gives a better $\mathrm{z}_{\mathrm{b}}$ and $I$. The thicker ribs have better fire resistance. The intervening slab concrete cast against the edges of the p.c. units provide a less severe discontinuity than units butted together. There is more room for cutting holes for ducts etc.

\section{Cross Braced Frames}

Not long ago, eminent Californian Engineers having seen earthquake failures of traditional wind bracing, joined in condemning the use of diagonal bracing in building frames, water towers, etc. This cannot be accepted as a rule and it seems that architects would do well to develop designs that would accommodate such bracing. It is interesting to see that some large buildings have been constructed in U.S.A., with diagonally braced walls, and their performance when subjected to earthquakes will be of considerable further interest. It is claimed that a cost saving of $\$ 15,000,000$ was gained by using diagonal bracing in the 100 storey John Hancock Centre. It is difficult to decide if this building is a good design or not. The fact that earthquake overturning forces are shared by the bracing among all the columns along the "windward" and "leeward" walls instead of being concentrated largely in the corner columns, confers economy and brings into the analysis as primary forces, effects which are secondary effects in open frame design and which therefore can constitute an interference with member design and with structural layout. 
Water-filled Columns

The 64 storey Pittsburgh Building of the U.S. Steel Corporation has hollow columns of corten steel which are full of water, and is the first major building having its Fire Resistance Rating provided by the cooling effect of the water.

The matter of Fire Resistance in seismic areas is very complex. To throw in one generalisation it seems advisable to put emphasis more on means of delaying the spread of fire rather than on endurance of structural strength.

\section{Ball Bearings}

It is naive to dream of the simplified concept of a building on ball bearings which remains unmoved when the earth moves under it. This type of structure has commonly been dismissed as unpractical. Professor Matshushika has been researching the subject of ball bearing supports and three other similar styles. It is reported that his ideas have been theoretically perfected.

Even without a free sliding base the endurance of buildings often owes a great deal to soil yield, and it is quite possible to relieve to a large degree the building acceleration by design of foundations to allow controlled displacement or rocking.

It would also seem possible to relieve forces on stiff buildings such as those with concrete block walls, by providing for relative movement in horizontal planes at the ceiling space at each storey.

\section{Mechanism in Buildings}

There would seem to be a scope for incorporating mechanisms to sense the movements and forces and to activate control on dimensions and restraints. One can envisage, for example, having columns surrounded at their lower ends by sleeves filled with mercury. The mechanism could control rocking and laterai displacement and provide energy dissipation through mercury dashpots. At the present we have too rough an idea of incident ground motions to take proper advantage of such a proposal.

\section{Damping}

Structural damping was first of all incorporated in structures as an unconsidered incidental property. Unfortunately, most of the damping has been provided by elements which suffered in the process. It would be a tremendous advantage to incorporate 
damping which would come into effective action before large motions are built up in the structure. There seems no reason why this cannot be done in various ways.

\section{Future Studies in New Zealand}

Engineers are much concerned with the newly formed group, a technical group within the New Zealand Institution of Engineers. We have hopes that this will prove to be a live executive organisation, able to command funds and well served by the stable secretariat of the Institution. Technical Groups of the Institution are open for full participation by people who are not members of the Institution and this Group should serve for dissemination and exchange of views of scientists, researchers and designers. It is also to be hoped that it will exercise an effective power in encouraging the lines along which research and design should be directed.

What desirable lines of development can be suggested? The financial limitations that exist in a small country make it essential that we set out to make a good and thorough job of a few facets of the problem rather than spread our efforts thinly. There should be some scope for effort unfettered by directives, but we will do more to justify grants of public money and do more to win further grants if we can achieve something which reduces the risk of earthquake damage in New Zealand. It is suggested that microzoning, and the interaction of soils and structure are two related matters deserving of a concentrated attack. The more mundane matters of defence against fire damage and the introduction of incentives into our insurance schemes could be even more important in reducing cost of damage from earthquakes.

Do you not think that a textbook or manual on the subject of anti-seismic design in New Zealand could be produced? Has the situation been reached where the output of individual studies of aspects of the problem even in New Zealand, is producing a mass of useful but insufficiently related works of reference which should be colated and published in one unit? Those of you who have made intensive efforts in these studies should realise that you are in a special position of acquaintance with other special studies and that there are many for whom the need of colation and co-ordination is greater.

\section{Perspective}

The studies to be presented to us are all part of the endeavour to succeed which is constantly being made by mankind. 
In what direction do we want to achieve success and how should our studies be directed and used for the benefit of mankind. Today, mankind can be fairly described as an interesting animal species proliferating on the face of this planet at such a rate that, in its wriggling fecundity it threatens to cause the extinction of other forms of animal and vegetable life and to threaten destruction of the conditions in which mankind itself could best develop.

In this situation our main aim should be to improve the quality of human life and not to increase the population. Out of this generality we have to consider as a particular problem, how much we should direct our endeavours towards the prevention of fatalities from earthquake destruction. This country is cluttered with securo-pathic people who urge the saving of a life is worth unlimited expenditure. They shrink from a scheme which, because of incomplete data would expose us to the risk of an occasional failure and would throw away the expectation of overall benefit. They seem able to exonerate themselves from any responsibility for supporting changes that would benefit the more vulnerable buildings if there is any suggestion that the proposed changes result in relaxation of requirements for buildings that are inherently safer. This point was very apparent in the zoning argument and the changes to the loadings code that were actually introduced with zoning, have resulted in greater strength requirement in all zones for all structures except those less common ones which have a longish natural period.

The point may be summarised by saying that the expenditure of an extra $\$ 100$ million per annum on making our buildings more safe could be expected to save perhaps half a dozen lives per year. That $\$ 100$ million could be otherwise spent to save a much larger number of lives, or could be used still more intelligently to restrict growth of population and concurrently provide a better life.

However our views may differ on these matters, we will probably agree that any progress in engineering which enables us to save money in achieving the same result or a better result, will release the resources of society to be devoted to securing other benefits. The traditional role of the engineer, pursuing improvements in efficiency, remains as the engineer's primary duty to society. 


\section{References}

(1) Evison, F.F.:

(2) Shepherd, R., and Travers,J.H.:

(3) Shepherd,R., and Walpole,W.R.:

(4) Shepherd, R., and Donald,R.A.H.:

(5) Taylor, P.W., and Hughes, J.M.D.:

(6) Taylor, P.W.:

(7)

(8) Garden,R.J.P.:

(9) Knowles, R.B.:
Summary Report, Session III (Seismicity and Earthquake Ground Motion), Proceedings 3rd World Conference on Earthquake Engineering.

"Surface Layer Modification of Seismic Waves", 40th A.N.Z.A.A.S. Conference, Christchurch, New Zealand, Jan. 1968.

"The Dynamic Interaction of Structures and Soils", New Zealand Engineering, 21 (2) $56-62,1966$.

"Foundation Deformation Effects in Structural Dynamic Analysis", Proceedings, Fifth Australia and New Zealand Soil Mechanics Conference. Auckland, Feb. 1967.

"Dynamic Properties of Foundation Subsoils as Determined from Laboratory Tests", Proceedings, 3rd World Conference on Earthquake Engineering, 1967.

"Design of Spread Footings for Earthquake Loadings", Proceedings, Fifth Australia and New Zealand Soil Mechanics Conference, Auckland, Feb. 1967.

N.Z. Standard Specification 1900, 1965, Chapter 8, "Basic Loads to be used in Design and their Method of Application", N.Z. Standards Institute, Wellington.

"A Slaughterhouse Extension at Burnside" New Zealand Engineering, 21 (6) 253-256, 1966 .

"Steel Tube Columns Infilled with Concrete", Unpublished M.E. Thesis, University of Canterbury, 1967. 